\title{
Myotonic Dystrophy: An Electrophysiological Study of Cognitive Deficits
}

\author{
Aldo Ragazzoni, Francesco Pinto, Rosanna Taiuti and Maria Caterina Silveri
}

\begin{abstract}
Patients with Myotonic Dystrophy (MyD) frequently suffer from a dysfunction of the primary sensory pathways, as documented by abnormalities of short-latency evoked potentials. Impairment of intellectual functions has been less extensively investigated. Short-latency brainstem auditory evoked potentials (BAEPs) as well as long-latency auditory event-related potentials (ERPs) were recorded from 5 female and 6 male patients affected by MyD. A simple discrimination ("oddball") paradigm was used to record ERPs to tones from $\mathrm{Fz}, \mathrm{Cz}, \mathrm{Pz}$. Both BAEPs and ERPs were significantly altered as compared to normals. BAEP abnormalities were detected in 9 patients and ERP components N2 and P3 were delayed or absent for all patients, who nonetheless correctly discriminated between tones. These data indicate that CNS dysfunction in MyD involves not only primary sensory systems but also neural mechanisms underlying cognitive events and ERP generation.
\end{abstract}

RÉSUMÉ: Dystrophie myotonique : étude électrophysiologique du déficit cognitif. La Dystrophie Myotonique (DM) est généralement associée à des dysfonctions des afférences senorielles, comme cela a été mis en évidence par les modifications des potentiels évoqués précoces. Les troubles des fonctions supérieures dus à la DM ont été plus rarement étudiés. Nous avons enregistré les potentiels évoqués auditifs du tronc cérébral (brainstem auditory evoked potentials : BAEPs) et les potentiels lents cérébraux (Event-Related Potentials : ERPs) de 5 femmes et 6 hommes atteints de DM. Les ERPs ont été recueillis dans un protocole de discrimination auditive ("oddball") en $\mathrm{Fz}, \mathrm{Cz}$ et $\mathrm{Pz}$. Nos résultats montrent à la fois une altération significative des BAEPs et des ERPs chez ces sujets par rapport aux témoins. Les BAEPs sont modifiés chez 9 d'entre eux, et les composantes N2 et/ou P3 des ERPs sont rétardées ou supprimées chez tous les patients, et ceci malgré une bonne discrimination auditive. Ces données montrent que les dysfonctions observées dans la DM ne concernent pas uniquement les systèmes sensoriels primaires, mais aussi des mécanismes neuronaux sous-tendant les processus cognitifs et impliqués dans la génération des ERPs.

Can.J. Neurol. Sci. 1991; 18:300-306

Myotonic Dystrophy (MyD), an autosomal inherited multisystemic disorder, was originally characterized in terms of myotonia and muscular wasting. I It was subsequently found to involve the central nervous system (CNS) as well, including structural abnormalities such as cerebral atrophy, ${ }^{2}$ thalamic neuronal inclusions, 3.4 ectopic isles of cortical tissue in white matter and discrete histologic anomalies in the frontal and occipital lobes. ${ }^{5}$ Magnetic resonance-imaging (MRI) studies have recently revealed focal white matter and temporal lobe abnormalities. 6.7

On the functional side, electrophysiological investigations have shown MyD patients to have a high incidence of abnormalities in their electroencephalograms (EEGs) and evoked potentials (EPs). EEG alterations include a slowing of the background activity, focal abnormalities and a peculiar low-frequency alpha rhythm $8-11$ as well as a disturbed EEG sleep pattern associated with central apnea. ${ }^{12,13}$ Modifications in short-latency EPs in three modalities (auditory, somatosensory, visual) have been reported in a number of studies, pointing to frequent subclinical involvement of the CNS sensory pathways. ${ }^{14-22}$ We have reported anomalies attributable to dysfunction of the central visual pathways, namely an increase in retino-cortical activation time, in $70 \%$ of MyD patients. ${ }^{23}$

Although short-latency EPs provide useful information about relatively simple sensory functions of the neuraxis, they are not sensitive to defects of higher neural functions. Indeed, the most frequent and clinically relevant CNS dysfunction in MyD is intellectual impairment which, although it can affect up to $70 \%$ of the patients, ${ }^{24}$ has been explored only in a few neuropsychological studies. ${ }^{25-27,13}$

Scalp recorded event-related potentials (ERPs) have lately gained popularity in the clinical context as a tool for assessing cognitive deficits. ${ }^{28}$ In particular, components N2 and P3 (or P300) of these long-latency EPs have proven to be sensitive to the information content of the eliciting stimulus (rather than to its physical properties) and have been associated with cognitive processing. ${ }^{29}$

From the Department of Neurological and Psychiatric Sciences, University of Florence, Florence, Italy (A.R., F.P., R.T.) and the Institute of Neurology, Catholic University, Rome, Italy (M.C.S.)

Received July 31, 1990. Accepted in final form February 22, 1991

Reprint requests to: Prof. F. Pinto, Dipartimento di Scienze Neurologiche e Psichiatriche, Universita' di Firenze, Viale Morgagni, 8550126 Firenze, Italy 
ERPs moreover, have been reported to be altered in dementias as well as in a number of neurological and psychiatric disorders involving cognitive defects. ${ }^{30-35}$ Alterations in the P300 component of auditory ERPs were noted in a group of MyD patients; ${ }^{35}$ these investigators confined their study to this component only and provided no neuropsychological data.

In response to auditory stimulation, we recorded both longlatency ERPs and short-latency brainstem evoked potentials (BAEPs) in a group of confirmed MyD patients, who also underwent neuropsychological testing. Our aim was to obtain an overall view of CNS dysfunction in MyD by examining in each patient the neural transmission through the fast-conducting brainstem auditory pathways as well as the subsequent intracerebral processing of the acoustic signals. We sought to establish whether there is a pattern of cognitive dysfunction peculiar to MyD by analyzing in detail the various ERP components $(\mathrm{N} 1, \mathrm{P} 2, \mathrm{~N} 2, \mathrm{P} 3)$ thought to reflect specific stages of information processing. ${ }^{29}$

\section{Materials ANd Methods}

The subjects (members of 5 family groups, 5 females and 6 males, age range 17-79 years, mean 44) were MyD patients with the typical myotonic phenomenon. None of the patients was being medicated with any psychoactive drugs. The diagnosis was based on characteristic neuromuscular findings, systemic alterations, typical electromyographic abnormalities and dominant inheritance. Based on the degree of myotonia, muscular wasting and weakness (cf. 23), the disease was classified as severe in 4 patients, moderate in 4 and mild in the remainder (Table 1).

Table 1: Clinical and Neuropsychological Findings in MyD Patients

\begin{tabular}{ccccc}
\hline \hline Sex & & & Disease & Disease \\
& Age & $\begin{array}{c}\text { Raven } \\
\text { duration } \\
\text { (yrs) }\end{array}$ & $\begin{array}{c}\text { Progressive } \\
\text { (yrs) } \\
\text { (motor } \\
\text { disability) }\end{array}$ & $\begin{array}{c}\text { Matrices } \\
\text { (relative } \\
\text { performance } \\
\text { level }{ }^{t} \text { ) }\end{array}$ \\
\hline
\end{tabular}

\begin{tabular}{lcrrrl}
\hline Patient & & & & & \\
$1^{*}$ & $\mathrm{~F}$ & 52 & 10 & 3 & 2 \\
$2^{*}$ & $\mathrm{M}$ & 25 & 13 & 2 & 3 \\
$3^{* *}$ & $\mathrm{~F}$ & 47 & 10 & 2 & 0 \\
$4^{* *}$ & $\mathrm{~F}$ & 24 & 6 & 1 & 1 \\
$5 * *$ & $\mathrm{M}$ & 17 & 4 & 1 & 1 \\
$6^{* *}$ & $\mathrm{M}$ & 52 & 12 & 3 & 0 \\
$7 * *$ & $\mathrm{~F}$ & 49 & 12 & 3 & 0 \\
$8^{* * *}$ & $\mathrm{M}$ & 42 & 2 & 1 & 0 \\
$9^{* * *}$ & $\mathrm{M}$ & 47 & 10 & 2 & 2 \\
10 & $\mathrm{~F}$ & 79 & 19 & 2 & 0 \\
11 & $\mathrm{M}$ & 49 & 15 & 3 & 1 \\
\hline & & & & &
\end{tabular}

$$
\begin{array}{ll}
*, * *, * * *=\text { familial cases } & \\
1=\text { mild } & 0=\text { normal } \\
2=\text { moderate } & 1=\text { mildly impaired } \\
3=\text { severe } & 2=\text { moderately impaired } \\
& 3=\text { severely impaired } \\
& \text { judged in terms of subject's age group }
\end{array}
$$

\section{Neuropsychological Testing}

The cognitive functions of MyD patients were evaluated by a battery of neuropsychological tests sampling memory, attention, visuospatial analysis, psychomotricity and "higher-level" processes (Rey test 1958, Digit Span and Association of Symbol and Digit, Visual Memory, Double Barrage, Word Fluency and Raven Progressive Coloured Matrices 47). The results were compared to those from a control group of 20 normal subjects, matched for age and sex. A score falling below the mean normal value by $1 \mathrm{SD}$ or more on at least 3 tests was regarded as a significant degree of intellectual deterioration.

\section{Electrophysiological Testing}

Electrophysiological testing was carried out in a quiet room with patients in a comfortable sitting position.

\section{Brainstem Auditory Evoked Potentials}

BAEPs were elicited by $70 \mathrm{~dB}$ SL rarefaction clicks delivered at the rate of $10 / \mathrm{sec}$, monaurally to each ear, through TDH39 earphones. Brain electrical activity was recorded through subcutaneous stainless steel needles inserted at $\mathrm{Cz}$ (International 10-20 system) and right (M2) and left (M1) mastoids. A ground electrode was applied to the forehead. For each individual two averages of 2000 responses from left and right ear stimulation were obtained, with a filter setting of $200-2000 \mathrm{~Hz}(-6 \mathrm{~dB})$ and analysis time of $20 \mathrm{msec}$ (sampling interval: 19 usec).

All the peak (I, II, III, IV, V) and interpeak latencies (IPLs: IIII, III-V, I-V) as well as the IV-V/I amplitude ratio were measured by means of a digital cursor on the computer screen. Results were compared with normative data obtained in a group of 40 normal adults, matched for age and sex. IPLs were considered abnormal when they exceeded mean normal values by 3 SD or more. A IV-V/I amplitude ratio $<0.5$ was considered abnormal.

\section{Event-Related Potentials}

ERPs were obtained by means of a simple "oddball" paradigm using auditory stimulation. Two successive series of randomly intermixed tones $(1000 \mathrm{~Hz}$, overall probability $85 \%$; $2000 \mathrm{~Hz}$, probability $15 \%$ ) were delivered binaurally through earphones at a rate of one tone ( $70 \mathrm{~dB} \mathrm{SL}, 50 \mathrm{msec}$ plateau time, $2 \mathrm{msec}$ rise and fall slopes) every $1.1 \mathrm{sec}$. Subjects were required to keep a mental count of the rare tones and to report the number at the end of each series. EEG activity was recorded (filter bandpass: $0.1-100 \mathrm{~Hz}$; analysis time: $1 \mathrm{sec}$; sampling interval: $1.07 \mathrm{msec}$ ) from scalp $\mathrm{Ag} / \mathrm{AgCl}$ electrodes at $\mathrm{Fz}, \mathrm{Cz}$, $\mathrm{Pz}$ (International 10-20 system), all referred to linked earlobe electrodes. Interelectrode impedance was always reduced to below $3000 \mathrm{ohms}$. Eye movements (electroculogram: EOG) were monitored through electrodes located on the nasion and the left zygomatic bone. Trials that contained EOG artifacts exceeding $100 \mu \mathrm{V}$ were automatically rejected from the averages. Responses to frequent $(\mathrm{N}=100)$ and rare $(\mathrm{N}=28-30)$ tones were averaged separately and stored on flexible diskettes for off-line analysis. In each individual two series of responses were recorded and superimposed to check for reproducibility of components. In addition, digital subtraction of the "frequent" from "rare" waveforms yielded "difference" waveforms which permitted better identification of the N2 and P3 components. Peak 
latency and amplitude (peak-to-peak voltages) of components $\mathrm{N} 1, \mathrm{P} 2, \mathrm{~N} 2, \mathrm{P} 3$ were measured in the averaged responses to the "rare" tones in MyD patients and these data were compared with those obtained from 36 age and sex-matched normal controls (age range 20-73 years, mean 42 ).

In our normal subjects, the latency of the P3 component increased significantly as a function of age, at a rate of 1.06 msec/year $(r=0.57, p<0.001)$. Therefore, an MyD individual's P3 latency was defined as abnormal when it fell beyond the 95\% confidence limits of the regression line relating P3 latency to age for our 36 controls. The latencies of components N1, P2 and N2, instead, as well as the amplitudes of all ERP components did not significantly change with age. On any of these ERP parameters, an MyD patient's value was considered abnormal when it deviated by 2.5 SDs or more from the corresponding mean of the control group.

In presenting and discussing our findings, we will concentrate on the data from the $\mathrm{Cz}$ electrode, where ERP components from normal subjects had their amplitude maxima.

\section{RESULTS}

\section{Neuropsychological Testing}

The psychometric assessment showed that 5 patients (patients 1, 4, 5, 9 and 11) had mild to moderate mental deficit, as measured by the Raven Progressive Matrices (RPM), and one (patient 2) was mentally retarded (Table 1); all patients, however, exhibited cognitive impairment of varying degree, particularly on tests involving visuo-spatial analysis and motor abilities (Double Barrage; Association of Symbol and Digit) which they performed poorly and very slowly.

\section{Brainstem Auditory Evoked Potentials}

Mean peak and interpeak latencies for BAEPs from the control group are presented in Table 2. Our SD values for all IPLs were somewhat lower than those reported by other researchers
(37), which may be due to our low frequency cut-off of $200 \mathrm{~Hz}$, instead of the more commonly used $100 \mathrm{~Hz}$ or less.

All patients presented normal click hearing thresholds and BAEPs with normal IV-V/I amplitude ratios and wave I latencies. In 9 out of 11 patients, however, the latencies of waves III and/or $\mathrm{V}$ were abnormally prolonged, and their IPLs exceeded normal means by more than 3 SDs (Table 3 ).

The IPL most often prolonged was I-V (in 13 out of 22 ears; in 4 patients it was bilaterally abnormal). The I-III IPL was abnormal in 7 ears (in 2 patients bilaterally) and the III-V IPL was altered in 8 ears (bilaterally so in 3 patients).

\section{Event-Related Potentials}

Table 2 lists mean latencies and amplitudes for each ERP component in our normal sample. ERP waveforms recorded in a normal subject and in a representative patient are presented in Figure 1.

During ERP recording all but one (patient 2) of the patients performed well on the counting task, detecting the rare stimuli with an accuracy greater than $90 \%$ (comparable to that of the normal controls whose mean percentage of correct detection "hits" - was 94, with an SD of 7). ERP analysis, however, revealed abnormalities in all patients. The earlier components,

Table 2: Electrophysiological Measures in Normal Controls (mean $+\mathrm{SD})$

\begin{tabular}{lllrr}
\hline \hline & BAEPs & \multicolumn{3}{c}{ Event-Related Potentials (at Cz) } \\
Interpeak Latencies (msec) & \multicolumn{2}{c}{ Latencies (msec) } & Amplitudes (uV) \\
\hline I-III & $2.02+0.12$ & N1 & $94+8.6$ & $7.1+2.5$ \\
III-V & $1.87+0.10$ & P2 & $154+10.2$ & $8.7+8.7$ \\
I-V & $3.90+0.13$ & N2 & $205+17.1$ & $5.5+3.6$ \\
& & P3* & $331+28.3$ & $15.7+6.5$ \\
\hline
\end{tabular}

* Latency of component P3 increased significantly as a function of age (slope: $1.06 \mathrm{msec} / \mathrm{year}$; intercept: $286.8 \mathrm{msec}$; $: 0.57$; $<<0.001$ )

Table 3: Electrophysiological Findings in MyD Patients

\begin{tabular}{|c|c|c|c|c|c|c|c|c|c|c|c|c|c|c|c|}
\hline \multirow[b]{3}{*}{ Patient } & \multicolumn{6}{|c|}{$\frac{\text { BAEPS }}{\text { Interpeak Latencies }}$} & \multicolumn{9}{|c|}{ Event-Related Potentials } \\
\hline & \multicolumn{2}{|c|}{ I-III } & \multicolumn{2}{|c|}{ III-V } & \multicolumn{2}{|c|}{$\mathrm{I}-\mathrm{V}$} & \multirow{2}{*}{$\begin{array}{c}\% \\
\text { hits }\end{array}$} & \multicolumn{2}{|c|}{$\mathrm{N} 1$} & \multicolumn{2}{|c|}{$\mathrm{P} 2$} & \multicolumn{2}{|c|}{$\mathrm{N} 2$} & \multicolumn{2}{|c|}{ P3 } \\
\hline & $\mathbf{R}$ & $\mathrm{L}$ & $\mathbf{R}$ & $\mathrm{L}$ & $\mathrm{R}$ & $\mathrm{L}$ & & lat. & amp. & lat. & amp. & lat. & amp. & lat. & amp. \\
\hline 1 & $\mathbf{N}$ & $\mathbf{N}$ & $N$ & $\mathbf{N}$ & $\mathbf{N}$ & $\mathbf{N}$ & 93 & $\mathbf{N}$ & $\mathbf{N}$ & A & $\mathbf{N}$ & A & $\mathbf{N}$ & A & $\mathbf{N}$ \\
\hline 2 & A & $\mathrm{N}$ & A & $\mathbf{N}$ & $\mathrm{A}$ & $\mathbf{N}$ & $58 \mathrm{~A}$ & $\mathbf{N}$ & $\mathbf{N}$ & $N$ & $\mathbf{N}$ & - & - & - & - \\
\hline 3 & $N$ & $\mathbf{N}$ & $N$ & $\mathbf{N}$ & $\mathbf{N}$ & A & 92 & $\mathrm{~N}$ & $\mathbf{N}$ & $\mathbf{N}$ & $\mathbf{N}$ & A & $\mathbf{N}$ & A & $\mathbf{N}$ \\
\hline 4 & $\mathrm{~N}$ & $\mathbf{N}$ & $\mathbf{N}$ & $\mathbf{N}$ & A & A & 93 & $\mathbf{N}$ & $\mathrm{N}$ & $\mathrm{N}$ & $\mathrm{N}$ & - & - & - & - \\
\hline 5 & A & $\mathrm{N}$ & $\mathbf{N}$ & A & A & $A$ & 97 & $\mathrm{~N}$ & $\mathbf{N}$ & $\mathrm{N}$ & $\mathbf{N}$ & - & - & - & - \\
\hline 6 & $\mathbf{N}$ & $\mathrm{N}$ & A & A & A & A & 98 & $\mathrm{~N}$ & $\mathbf{N}$ & A & $\mathrm{N}$ & $\mathrm{A}$ & $\mathbf{N}$ & $\mathrm{N}$ & $N$ \\
\hline 7 & A & A & $\mathbf{N}$ & $\mathrm{N}$ & A & A & 99 & $\mathbf{N}$ & $\mathrm{N}$ & A & $\mathrm{N}$ & A & $\mathbf{N}$ & $\mathbf{N}$ & $\mathbf{N}$ \\
\hline 8 & $\mathbf{N}$ & $\mathbf{N}$ & $\mathbf{N}$ & $\mathbf{N}$ & $\mathrm{N}$ & $\mathrm{N}$ & 98 & $\mathbf{N}$ & $\mathbf{N}$ & A & $\mathrm{N}$ & A & $\mathbf{N}$ & - & - \\
\hline 9 & $\mathbf{N}$ & A & $\mathbf{N}$ & $\mathbf{N}$ & $\mathbf{N}$ & A & 91 & A & $\mathbf{N}$ & A & $\mathbf{N}$ & A & $\mathbf{N}$ & $\mathbf{N}$ & $\mathbf{N}$ \\
\hline 10 & $\mathbf{N}$ & $\mathbf{N}$ & A & A & A & $\mathbf{N}$ & 100 & $\mathbf{N}$ & $\mathrm{N}$ & $\mathbf{N}$ & $\mathbf{N}$ & A & $\mathbf{N}$ & A & $N$ \\
\hline 11 & A & A & A & A & $\mathrm{A}$ & $\mathbf{N}$ & 100 & $\mathrm{~N}$ & $\mathbf{N}$ & $\mathbf{N}$ & $\mathbf{N}$ & - & - & - & - \\
\hline
\end{tabular}

$\mathrm{L}=$ left ear stimulation; $\mathrm{R}=$ right ear stimulation

$\%$ hits = percentage of rare tones correctly detected

$\mathrm{N}=$ normal value; $\mathrm{A}=$ abnormal value; - = non-identifiable component 


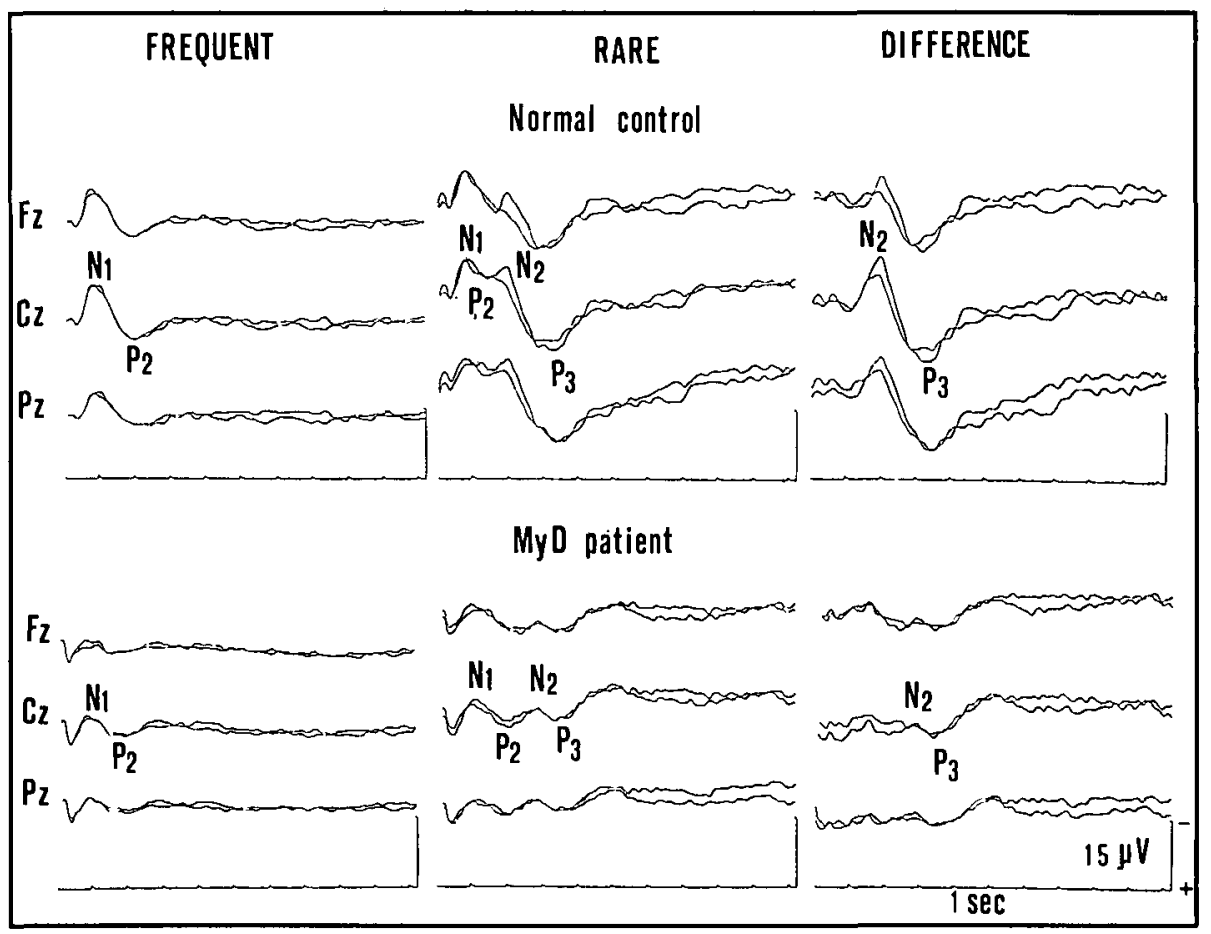

Figure 1: - Event-related potentials in response to frequent and rare tones in a 49-year-old normal female (upper part) and in patient 7 (female, age 49). The "difference" waveforms obtained by the subtraction of the "frequent" waveforms from the "rare" waveforms are also shown. Latencies of components $P 2$ and N2 were significantly prolonged in the patient's waveforms.

$\mathrm{N} 1$ and $\mathrm{P} 2$, were proportionately less altered (in $9 \%$ and $45 \%$ of the patients) while component $\mathrm{N} 2$ was modified in $100 \%$ and P3 in $73 \%$ of the cases. More precisely, while the latency of $\mathrm{N} 1$ was significantly slowed in only one patient and that of P2 in five, N2 was affected in all: its latency was abnormally lengthened in seven patients and this component could not even be identified in four. P3 could not be detected in five patients, four of which had a missing N2. For the other MyD patients, P3 latency was significantly increased in three of them (amplitudes remaining normal), while for the remainder, both $\mathrm{P} 3$ latency and amplitude fell within the normal range (Table 3 and Figure 2). Overall, ERPs were more altered in younger patients (patients 2, $4,5)$ for whom neither component N2 nor P3 could be recorded (Figure 3 ). These patients, all offspring of affected parents, had manifested an earlier disease onset than their parents and all showed impairment in the neuropsychological investigation.

BAEP and ERP changes were not correlated with the disease's duration or severity (expressed as degree of motor disability): none of the Fisher exact test values (BAEP and ERP latencies vs disease duration and severity) turned out to be significant ( $p$ always $>0.05$ ). A significant negative correlation, however, was found for MyD patients between latency of component N2 and their RPM score (Kendall rank correlation coefficient: $-0.529 ; p<0.01$ ).

\section{Discussion}

The most striking finding of the present study is that $100 \%$ of our MyD patients showed electrophysiological anomalies reflecting CNS dysfunction. These neurophysiological abnor-

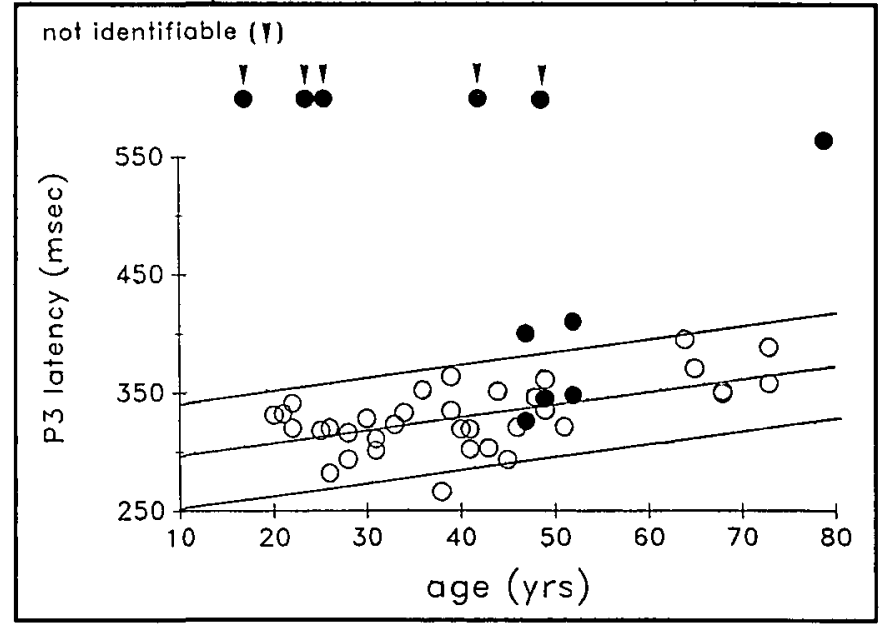

Figure 2: - P3 latencies at $C_{z}$ plotted as a function of age. Linear regression line is shown together with $95 \%$ confidence limits as calculated on data obtained from 36 normal controls (slope: $1.06 \mathrm{msec} /$ year; intercept: $286.8 \mathrm{msec}$; $S E: 23$ msec: $r: 0.57: P$ <0.001). Open circles: normal controls. Filled circles: $M y D$ patients. Not identifiable: components impossible to identify.

malities were unrelated both to the motor deficits caused by muscular degeneration and to the duration of the disease. Our results from $11 \mathrm{MyD}$ patients agree with those obtained on a larger population 27 which showed neuropsychological deficit in MyD to be largely congenital, independent of progressive motor symptoms and relatively stable over time. 


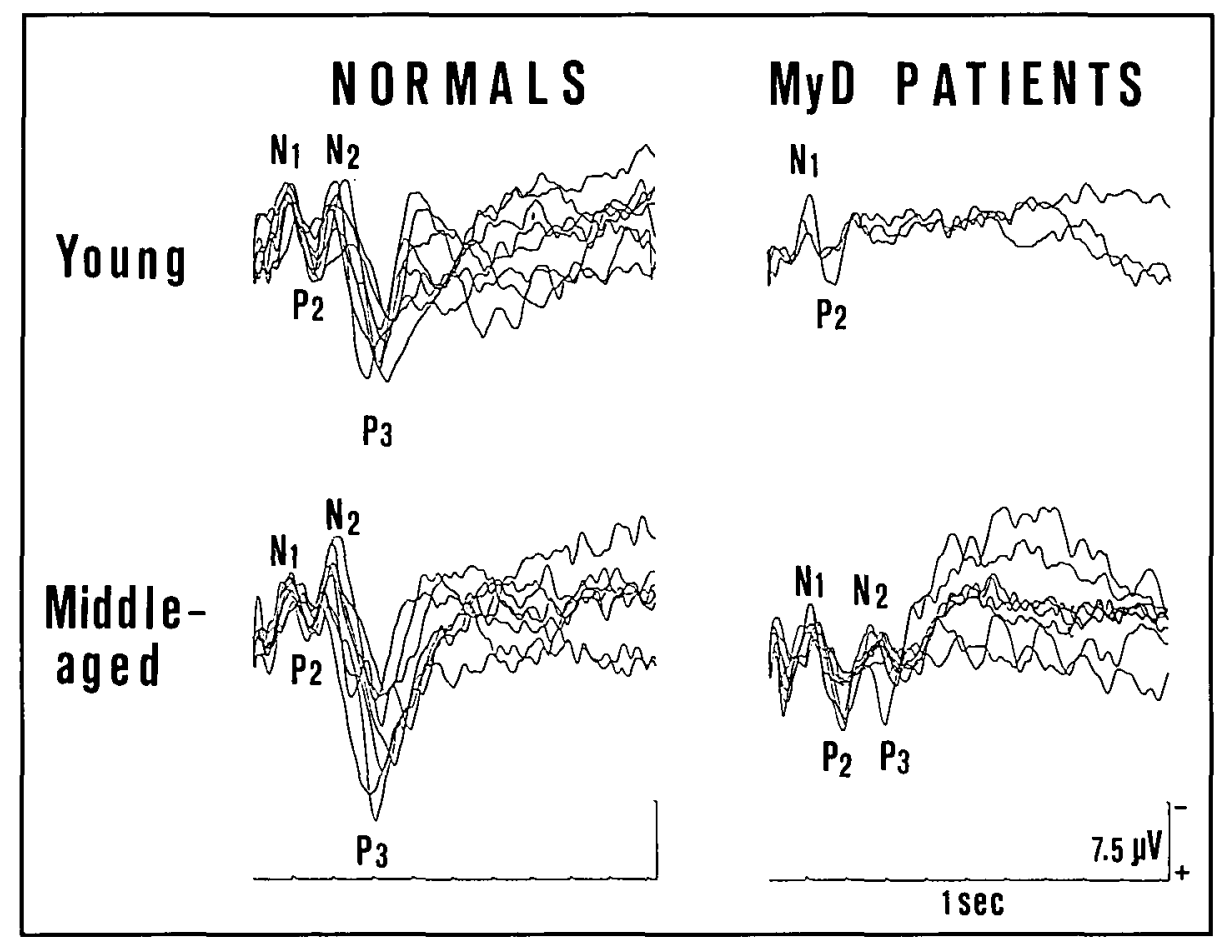

Figure 3: - Superimposed individual waveforms at $C z$ in response to rare tones in normal controls (left) and $M y D$ patients (right). For a better comparison, normals and patients are gathered in two groups matched for age (upper half: young individuals, including 8 normals and 3 patients; lower half: middle-aged individuals, including 8 normals and 7 patients). Note the retained NI and P2 components in the patient groups, with abnormal or unidentifiable N2 and P3. In all the three young patients' waveforms, components N2 and P3 are not identifiable.

The elctrophysiological procedures we employed (BAEPs and ERPs) explore the function of neural structures located at different CNS levels. BAEPs reflect the activity of fiber tracts and nuclei within the brainstem. ${ }^{38}$ ERPs are generated by activity and interaction of multiple neuronal sources in cortical and subcortical cerebral regions: the superior temporal plane and lateral superior temporal gyrus are recognized generators for component $\mathrm{N} 1 ; 39$ the frontal lobe, ${ }^{4}$ the temporo-parietal junction, ${ }^{41,42}$ limbic ${ }^{43}$ and thalamic ${ }^{44}$ structures have been proposed as possible sources of components N2 and P3.

The BAEP and ERP abnormalities we observed indicate a diffuse, often subclinical, involvement of the CNS implying: 1) a slowing of impulse propagation in central afferent fibers, already noted in a number of studies $16,18,21,23$ and similar to the reduction in sensory conduction observed in peripheral nerves, 45 and 2) a dysfunction of different neuronal populations in the brain, whose patterned activities underlie cognitive events and ERP generation.

In addition, the fact that BAEP and ERP anomalies tended to be associated in many but not all patients (see patients 1 and 8 in Table 3) supports the notion that the pathological process in MyD can separately affect different parts of the CNS.21

ERPs turned out to play the major role in detecting CNS malfunction: their $\mathrm{N} 2$ and $\mathrm{P} 3$ components were abnormal in all our MyD patients. Both components, obtained in an auditory "oddball" task, have been associated with cognitive processes: $\mathrm{N} 2$ has been linked with stimulus categorization ${ }^{46}$ while P3 may reflect psychological processes such as stimulus evaluation time, ${ }^{47}$ updating of an internal memory template subsequent to stimulus evaluation, ${ }^{48,49}$ and "controlled" cognitive processing. 50.51

On the other hand ERP component N1, thought to reflect earlier processes involved in sensory evaluation and selective attention as well as general level of arousal, ${ }^{39}$ was normal in 9 out of 11 patients. The preservation of this component (together with the patients' ability to correctly perform the counting task) rules out marked sensory defects or attention disturbances.

This points to a more subtle disorder in cognitive processing in our group of MyD patients, occurring after the perception of acoustic stimuli and reflected in the abnormalities of the N2 and P3 components of auditory ERPs.

It seems paradoxical that subjects who performed poorly on the neuropsychological test battery could achieve a $90 \%$ accuracy on the rare-tone counting task. The latter, however, involves a simple sensory discrimination basically unaffected in $\mathrm{MyD}$, whereas psychometric tests explore complex, higher mental functions that are compromised by the disease.

These ERP data agree with those of a previous study 36 in which P3 abnormalities were found in 6 out of 8 MyD patients. In our series of patients, however, the most altered component was N2, which was abnormal in the entire group and was also the only ERP component correlated with a global neuropsychological measure of cognition (the RPM test). Thus, in addition to $\mathrm{P} 3$, component $\mathrm{N} 2$ can serve as a sensitive index of cognitive impairment in different patient populations. $32,33,35,46$ 
On the clinical level, our findings point to the advisability of routinely recording evoked potentials in individuals affected by or at risk for MyD. EPs are particularly useful in localizing brain structures involved in the disease. ERPs moreover can reveal aspects of cognitive functions not measured by standard neuropsychological tests. Hence a combination of these procedures may yield a more accurate picture of cognitive functions in MyD patients and may be useful for purposes of educational and vocational counselling.

Our electrophysiological protocol has shown itself to be highly sensitive in detecting subclinical CNS malfunction, which may occur long before MyD symptoms become clinically evident. These neurophysiological techniques might therefore serve as a tool in the early detection of MyD and could be applied to relatives of MyD patients at risk for developing the disease.

\section{ACKNOWLEDGEMENTS}

We gratefully thank Dr. Ida Berger for her help in revising the English text and Mr. Arthur Falk for his thoughtful comments in the preparation of this manuscript.

\section{REFERENCES}

1. Steinert H. Myopatologische Beitraege. I. Dtsch. Z. Nervenheilk. 37: 58-104, 1909.

2. Refsum S, Lonnum A, Sjaastad O, et al. Dystrophia myotonica. Repeated pneumoencephalographic studies in ten patients. Neurology, 1957; 17: 345-348.

3. Culebras A, Feldman RG, Merk FB. Cytoplasmatic inclusion bodies within neurons of the thalamus in myotonic dystrophy. J. Neurol. Sci., 1973; 19: 319-329.

4. Wisniewski HM, Berry K, Spiro AJ, et al. Ultrastructure of thalamic neuronal inclusions in myotonic dystrophy. J. Neurol. Sci., 1975; 24: 321-329.

5. Rosman NP, Kakulas BA. Mental deficiency associated with muscular dystrophy: a neuropathological study. Brain 1966; 89: 769787.

6. Glantz RH, Wright RB, Huckman MS, et al. Central nervous system magnetic resonance imaging findings in myotonic dystrophy. Arch. Neurol. 1988; 45: 36-37.

7. Huber SJ, Kissel JT, Shuttleworth EC, et al. Magnetic resonance imaging and clinical correlations of intellectual impairment in myotonic dystrophy. Arch. Neurol., 1989; 46: 536-650.

8. Friedlander WJ, Bittenbender JB. EEG findings in myotonic dystrophy. Electroenceph. Clin. Neurophysiol., 1964; 17: 564-566.

9. Barwick DD, Osselton JW, Walton JN. EEG studies in hereditary myopathy. J. Neurol. Neurosurg. Psychiatry, 1965; 28: 109-114.

10. Lundervold A, Refsum S, Jacobsen W. The EEG in dystrophia myotonica. Eur. Neurol., 1969; 2:279-284.

11. Beijersbergen RSHM, Kemp A, Storm van Leeuwen W. EEG observation in dystrophia myotonica. Electroenceph. Clin. Neurophysiol., 1980; 49: 143-151.

12. Coccagna G, Mantovani L, Parchi $C$, et al. Alveolar hypoventilation and hypersomnia in myotonic dystrophy. J. Neurol. Neurosurg. Psychiatry, 1975; 38: 977-984.

13. Broughton R, Stuss D, Kates M, et al. Neuropsychological deficits and sleep in Myotonic Dystrophy. Can. J. Neurol. Sci., 1990; 17: 410-415.

14. Kirkham TH, Coupland SG. Myotonic Dystrophy: normal electroretinal function associated with visual evoked potential abnormalities. In: Huber MA, Klein D, eds. Neurogenetics and Neuroopthalmology. Amsterdam: Elsevier, 1981: 51 -58.

15. Gott PS, Karnaze DS, Keane R. Abnormal visual evoked potentials in myotonic dystrophy. Neurology, 1983; 33: 1622-1625.

16. Thompson DS, Woodward JB, Ringel SP, et al. Evoked potential abnormalities in myotonic dystrophy. Electroenceph. Clin. Neurophysiol., 1983; 56: 453-456.
17. Bartel PR, Lotz BP, Van der Meyden CH. Short-latency somatosensory evoked potentials in dystrophia myotonica. J. Neurol. Neurosurg. Psychiatry, 1984; 47: 524-529.

18. Bartel PR, Lotz BP, Robinson E, et al. Posterior tibial and sural nerve somatosensory evoked potentials in dystrophia myotonica. J. Neurol. Sci., 1985; 70: 55-65.

19. Gott PS, Karnaze DS. Short-latency somatosensory evoked potentials in myotonic dystrophy. Electroenceph. Clin. Neurophysiol., 1985; 65: 455-458.

20. Sandrini G, Gelmi C, Rossi V, et al. Electroretinographic and visual evoked potential abnormalities in myotonic dystrophy. Electroenceph. Clin. Neurophysiol., 1986; 64: 215-217.

21. Ganes T, Kerty E. Multimodal evoked potentials, EEG and electroretinography in patients with dystrophia myotonica. Acta Neurol. Scand., 1988; 78: 436-442.

22. Sartucci F, Marconi F, Busso E, et al. Multimodality evoked potentials in myotonic dystrophy. Ital. J. Neurol Sci., 1989; 10:61-67.

23. Pinto F, Amantini A, De Scisciolo G, et al. Electrophysiological studies of the visual system in myotonic dystrophy. Acta Neurol. Scand., 1987; 76: 351-358.

24. Zellweger H, Ionanescu V. Myotonic dystrophy and its differential diagnosis. Acta Neurol. Scand., 1973; Suppl. 55, 49: I-28.

25. Woodward J, Heaton RK, Simon D, et al. Neuropsychological findings in myotonic dystrophy. J. Clin. Neuropsychol., 1982; 4: 335342.

26. Bird T, Follett C, Griep E. Cognitive and personality function in myotonic muscular dystrophy. J. Neurol. Neurosurg. Psychiatry, 1983; 46: 971-980

27. Malloy P, Mishra SK, Adler SH. Neuropsychological deficits in myotonic muscular dystrophy. J. Neurol. Neurosurg. Psychiatry, 1990; 53: 1011-1013.

28. Picton TW, Hillyard SA. Endogenous event-related potentials. In: Picton TW, ed. Human Event-Related Potentials. Handbook of Electroencephalography and Clinical Neurophysiology, vol. 3. Revised Series. Amsterdam: Elsevier, 1988: 361-426.

29. Hillyard SA, Kutas M. Electrophysiology of cognitive processing. Ann. Rev. Psychol., 1983; 34: 33-61.

30. Goodin DS, Squires KC, Starr A. Long latency event-related components of the auditory evoked potentials in dementia. Brain, 1978; 101: 635-648.

31. Pfefferbaum A, Wenegrat BG, Ford JM, et al. Clinical applications of the P3 component of event-related potentials. Electroenceph. Clin. Neurophysiol., 1984; 59: 104- 124.

32. Goodin DS, Aminoff JA. Electrophysiological differences between subtypes of dementia. Brain, 1986; 109: 1103-1113.

33. Porjesz B, Begleiter H, Bihari B, et al. The N2 component of the event-related brain potential in abstinent alcoholics. Electroenceph. Clin. Neurophysiol. 1987; 66: 121-131.

34. Neshige R, Barrett G, Shibasaki H. Auditory long-latency eventrelated potentials in Alzheimer's disease and multi-infarct dementia. J. Neurol. Neurosurg. Psychiatry, 1988; 51: 11201125.

35. Newton MR, Barrett G, Callanan MM, et al. Cognitive event-related potentials in multiple sclerosis. Brain, 1989;112: 1637-1660.

36. Hanafusa $\mathrm{H}$, Motomura $\mathrm{N}$, Asaba $\mathrm{H}$, et al. Event-related potentials (P300) in myotonic dystrophy. Acta Neurol. Scand., 1989; 80: 111-113.

37. Picton TW. Auditory evoked potentials. In: Daly DD, Pedley TA, eds. Current Practice of Clinical Electroencephalography. New York: Raven Press, 1990: 625-678.

38. Chiappa KH. Brainstem auditory evoked potentials: interpretation. In: Chiappa $\mathrm{KH}$, ed. Evoked Potentials in Clinical Medicine. New York: Raven Press, 1990: 232-237.

39. Naatanen R, Picton T. The NI wave of the human electric and magnetic response to sound: a review and an analysis of the component structure. Psychophysiology, 1987; 24: 375-425.

40. Wood CC, McCarthy G. A possible frontal lobe contribution to scalp P3. Soc. Neurosci. Abstr., 1985; 11: 879.

41. Knight RT, Scabini D, Woods DL, et al. Contribution of temporoparietal junction to the human auditory P3. Brain Res., 1989; 502: 109-116. 
42. Smith ME, Halgren E, Sokolik M, et al. The intracranial topography of the P3 event-related potential elicited during auditory oddball. Electroenceph. Clin. Neurophysiol., 1990; 76: 235-248.

43. Halgren E, Stapleton JM, Smith M, et al. Generators of the human scalp P3(s). In: Cracco RQ, Bodis-Wollner I, eds. Evoked Potentials. Frontiers in Clinical Neurosciences, vol. 3. New York: Alan Liss, 1986: 269-284.

44. Yingling CD, Hosobuchi Y. A subcortical correlate of $\mathrm{P} 3$ in man. Electroenceph. Clin. Neurophysiol., 1984; 59: 72-76.

45. Olson ND, Jou MF, Quast JE, et al. Peripheral neuropathy in myotonic dystrophy. Arch. Neurol., 1978; 35: 741-745.

46. Naatanen R, Picton TW. N2 and automated versus controlled processes. In: McCallum WC, Zappoli R, Denoth F, eds. Cerebral Psychophysiology: Studies in Event-Related Potentials. Amsterdam: Elsevier, 1986: 169-186.

47. Magliero A, Bashore TR, Coles MGH, et al. On the dependence of P300 latency on stimulus evaluation processes: Psychophysiology, 1984; 21: 171-186.
48. Donchin E. Surprise!...Surprise? Psychophysiology, 1981; 18: 493513.

49. Pratt, $\mathrm{H}$, Michalewski HJ, Barrett $\mathrm{G}$, et al. Brain potentials in a memory-scanning task. l. Modality and task effects on potentials to the probe. Electroenceph. Clin. Neurophysiol., 1989; 72: 407421.

50. Wickens C, Kramer A, Vanasse L, et al. Performance on concurrent tasks: a psychophysiological analysis of reciprocity of information-processing resources. Science, 1983; 221: 1080-1082.

51. Gevins A, Cutillo BA. Signals of cognition. In: Lopes da Silva FH, Storm van Leeuwen W, Remond A, eds. Clinical Applications of Computer Analysis of EEG and Other Neurophysiological Signals. Handbook of Electroencephalography and Clinical Neurophysiology, vol. 2. Revised series. Amsterdam: Elsevier, 1985: 335-381. 